\title{
A dairy herd-level study of postpartum diseases and their association with reproductive performance and culling
}

\author{
J. Dubuc ${ }^{1}$ and J. Denis-Robichaud ${ }^{2}$ \\ Faculté de Médecine Vétérinaire, Université de Montréal, C.P. 5000, Saint-Hyacinthe, Québec, J2S 7C6, Canada
}

\begin{abstract}
The objectives of this study were to quantify the herd-level prevalence of postpartum diseases in a large number of dairy farms, and to identify prevalence alarm levels of these diseases based on association with a low prevalence of success at first service, with a high prevalence of pregnancy loss following pregnancy diagnosis at first service, and with a high prevalence of postpartum culling. A total of 126 commercial dairy herds were enrolled in this cohort study, and the herd was the unit of interest. Twenty cows from every herd were enrolled during the study period (a total of 2,520 lactating cows in the study). Cows were diagnosed with hyperketonemia, retained placenta, displaced abomasum, purulent vaginal discharge, cytological endometritis, leukocyte esterase endometritis, and prolonged anovulation. The prevalence of each of these diseases was computed for every herd. The study outcomes were the prevalence of success at first service, the prevalence of pregnancy loss following pregnancy diagnosis at first service, and the prevalence of postpartum culling ( $\leq 60 \mathrm{~d}$ in milk). Descriptive statistics of disease and outcome prevalence were computed. Logistic regression models were used to identify prevalence alarm levels associated with poor outcome prevalence. Median herd prevalence for hyperketonemia, retained placenta, displaced abomasum, purulent vaginal discharge, cytological endometritis, leukocyte esterase endometritis, and prolonged anovulation were $18.8,4.9,4.0,5.0,29.4,43.8$, and $35.2 \%$, respectively. Herds were defined as having low prevalence of success at first service if $<40.0 \%$, as having a high prevalence of pregnancy loss if $\geq 6.3 \%$, and as having a high prevalence of postpartum culling if $\geq 13.3 \%$. Risk factors for herds having a low prevalence of success at first service were $\geq 11.8 \%$ hyperketonemia, $\geq 5.0 \%$ purulent vaginal discharge, $\geq 18.8 \%$ cytological endometritis, $\geq 35.3 \%$ leukocyte esterase endometritis, $\geq 21.0 \%$
\end{abstract}

\footnotetext{
Received October 12, 2016.

Accepted December 12, 2016.

${ }^{1}$ Corresponding author: Jocelyn.dubuc@umontreal.ca

${ }^{2}$ Current address: Department of Population Medicine, University of Guelph, Guelph, Ontario, N1G 2W1, Canada.
}

prolonged anovulation, and $\geq 4.0 \%$ of displaced abomasum. Risk factors for herds having a high prevalence of pregnancy loss were $\geq 5.0 \%$ purulent vaginal discharge and $\geq 4.9 \%$ retained placenta. Risk factors for herds having a high prevalence of postpartum culling were $\geq 23.1 \%$ hyperketonemia, $\geq 4.9 \%$ retained placenta, and $\geq 4.0 \%$ displaced abomasum. Overall, postpartum diseases were prevalent in these dairy herds and alarm levels were identified as risk factors for poor reproductive performance and increased culling.

Key words: dairy, herd level, disease, reproduction, culling

\section{INTRODUCTION}

At the cow level, peripartum metabolic health is important to achieve subsequent high milk production and good reproductive performance (Duffield et al., 2009; Ospina et al., 2010b; Chapinal et al., 2012a). For example, cows experiencing postpartum hyperketonemia have a greater risk than normoketonemic cows of subsequently having displaced abomasum (Duffield et al., 2009; McArt et al., 2012), cytological endometritis (Dubuc et al., 2010b), low milk production (Duffield et al., 2009; McArt et al., 2012), early culling (McArt et al., 2012; Roberts et al., 2012), poor reproductive performance (Walsh et al., 2007; Ospina et al., 2010b; McArt et al., 2012), and pregnancy loss after diagnosis of pregnancy at first service (Santos et al., 2009). Similarly, many studies have shown an association between peripartum reproductive diseases and subsequent reproductive performance or culling. For example, cows affected by purulent vaginal discharge and cytological endometritis are likely to have a worse future reproductive performance than cows without reproductive tract diseases (Dubuc et al., 2011; Vieira-Neto et al., 2014; Denis-Robichaud and Dubuc, 2015a). Prolonged postpartum anovulation was also reported to be associated with a worse future reproductive performance (Walsh et al., 2007; Dubuc et al., 2012; Vieira-Neto et al., 2014).

All of these cow-level findings are very helpful to better understand the complex relationship between peripartum events and their effect on individual cows. 
However, farmers, veterinarians, and nutritionists work on a daily basis toward maintaining or improving the performance of the herd, not just individual cows. Even if this process implies dealing with problems at the cow level, the relationships found at the cow level might not hold true at the herd level. Implying that what is true at the cow level is automatically true at the herd level is an atomistic fallacy and should be avoided. For example, although it is known that hyperketonemia at the cow level is associated with a subsequent detrimental effect on reproduction, a study showed that only a prevalence $\geq 15$ to $20 \%$ of hyperketonemia in a herd was associated with a poorer reproductive performance at the herd level (Ospina et al., 2010a). It implies that even if hyperketonemia is detrimental at the cow level, it takes a certain proportion of cows affected in a herd to have a worse herd performance in reproduction. Another study reported similar herd-level associations between a high proportion $(\geq 30 \%)$ of cows with elevated prepartum blood nonesterified fatty acids (Chapinal et al., 2012b) and a poor herd reproductive performance.

Many validated diagnostic tools are available for cow-side use on farms to perform systematic postpartum disease surveillance. Cows can be monitored for hyperketonemia using the Precision Xtra (Iwersen et al., 2009), for purulent vaginal discharge using the Metricheck device (McDougall et al., 2007; Dubuc et al., 2010a; Denis-Robichaud and Dubuc, 2015a), for cytological endometritis using the cytobrush technique (Kasimanickam et al., 2004; Dubuc et al., 2010a; Denis-Robichaud and Dubuc, 2015a), and for leukocyte esterase endometritis using the leukocyte esterase test (Denis-Robichaud and Dubuc, 2015a). Prolonged anovulation is more difficult to monitor cow side but can be done by measuring progesteronemia or using ultrasonography (Galvão et al., 2010; Dubuc et al., 2012; Vieira-Neto et al., 2014). The alarm level of these conditions in dairy herds remains unclear (except for hyperketonemia). Some herd-level studies about the prevalence and risk factors for cytological endometritis and prolonged anovulation have been published (Walsh et al., 2007; Cheong et al., 2011), but none reported an acceptable prevalence or prevalence alarm level that could be considered for herd management. Unfortunately, the number of studies published in this field of research remains small, and it is difficult for dairy consultants to advise their clients about the acceptable prevalence of diseases without inferring recommendations from cow-level studies.

Therefore, the first objective of this study was to quantify the herd-level prevalence of postpartum diseases in a large number of dairy herds. The second objective was to identify herd prevalence alarm levels of these diseases based on association with a low preva- lence of success at first service. The third objective was to identify herd prevalence alarm levels of these diseases based on association with a high prevalence of pregnancy loss following pregnancy diagnosis at first service and of postpartum culling.

\section{MATERIALS AND METHODS}

A prospective cohort study was conducted in commercial dairy herds located within $150 \mathrm{~km}$ of the bovine ambulatory clinic of the Faculté de Médecine Vétérinaire of the Université de Montréal (St-Hyacinthe, Québec, Canada). For the first study objective, an estimated sample size of 73 herds (proportion expected $=5 \%$, $\alpha=5 \%$, precision of estimate $=5 \%$ ) was targeted for retained placenta, displaced abomasum, and pregnancy loss; of 61 herds (proportion expected $=20 \%, \alpha=5 \%$, precision of estimate $=10 \%$ ) for hyperketonemia, purulent vaginal discharge, cytological endometritis, leukocyte esterase endometritis, and postpartum culling; and of 92 herds (proportion expected $=40 \%, \alpha=5 \%$, precision of estimate $=10 \%$ ) for prolonged anovulation and success at first service. For the second objective, an estimated sample size of 126 herds was targeted based on having a disease prevalence difference of 20 percentage points in herds with different (high/low) success at first service (high reproductive performance estimated to have $10 \%$ disease prevalence vs. low reproductive performance estimated to have $30 \%$ disease prevalence) and accounting for $\alpha$ and $\beta$ errors of 5 and $20 \%$, respectively (Dohoo et al., 2003). The target population of this study were the herds enrolled in a veterinary preventive medicine program. Herd selection was based on convenience: all chosen herds were enrolled in a preventive medicine program involving veterinary visits every 2 wk or more frequently and systematically used an ovulation synchronization protocol for first service $(\mathrm{n}=135)$. These participating herds were visited every $14 \mathrm{~d}$ by a veterinarian and an animal health technician during data collection.

The herd was the unit of interest in this study. In every participating herd, a cohort of 20 cows was recruited to ensure a reasonable confidence in disease prevalence calculation, which was targeted to be around $20 \%$ for most diseases (Oetzel, 2004). Specifically, this sample size calculation (for diseases, success at first service, and culling) was based on the following assumptions: proportion expected $=20 \%, \alpha=25 \%$ (for a $75 \%$ CI), and precision of estimate $=10 \%$. For the sample size calculation of pregnancy loss, a sample size of 7 cows per herd was used and based on an expected proportion of $6 \%$, an $\alpha$ value of $25 \%$ (for a $75 \% \mathrm{CI}$ ), and a precision of estimate of $10 \%$. Selection of these cows was systematic during the sampling period: all cows 
were enrolled at calving until a total of 20 cows were recruited. Herds were sampled between May 2014 and August 2015.

\section{Hyperketonemia}

Every cow from this cohort was bled once between 1 and 14 DIM; a volume of $1 \mathrm{~mL}$ of blood was obtained from coccygeal vessels and ketonemia (BHB) was immediately tested using the Precision Xtra device (Abbott, Mississauga, Ontario, Canada). Analytical sensitivity of the device was $0.2 \mathrm{mmol} / \mathrm{L}$, and the maximum possible value was $7.2 \mathrm{mmol} / \mathrm{L}$. Cows were defined as hyperketonemic if they had blood BHB $\geq 1.4 \mathrm{mmol} / \mathrm{L}$ (Duffield et al., 2009). The prevalence of hyperketonemia was calculated by dividing the number of hyperketonemic cows by the number of all cows sampled.

\section{Purulent Vaginal Discharge and Cytological Endometritis}

Every cow in the cohort was also tested for purulent vaginal discharge and cytological endometritis between 30 and 43 DIM. For vaginal discharge, the Metricheck device technique and scoring $(0=$ no discharge, $1=$ clear mucus, $2=$ mucus with flecks of pus, $4=$ purulent discharge, or $5=$ foul-smelling discharge) were used (McDougall et al., 2007). For endometritis, a cytological sample was obtained from the body of the uterus using the cytobrush technique (Kasimanickam et al., 2004). After collection, the cytobrush was rolled on a glass slide for microscopic evaluation and subsequently plunged into an individual vial $(3 \mathrm{~mL})$ containing 1 $\mathrm{mL}$ of $0.9 \%$ saline solution $(\mathrm{NaCl} 0.9 \%$ Irrigation, Baxter Corp. Mississauga, Ontario, Canada) for leukocyte esterase testing. This leukocyte esterase test was performed immediately on the farm using a technique described elsewhere (Denis-Robichaud and Dubuc, 2015a). In summary, the saline vial was shaken for $10 \mathrm{~s}$ and a drop of solution was put on a leukocyte esterase commercial strip (Multistix 10 SG, Bayer Corporation, Elkart, IN). Test results were read after $2 \mathrm{~min}$ according to the manufacturer's recommendations $(0=$ negative, $0.5=$ trace amount of leukocytes, $1=$ small amount of leukocytes, $2=$ moderate amount of leukocytes, 3 = large amount of leukocytes). The microscope glass slide of every cow that was smeared with the cytobrush was brought back to the laboratory. Within 12 $\mathrm{h}$ of collection, the slide was stained using a modified Wright-Giemsa stain (Hema3, Biochemical Sciences, Swedesboro, NJ) and a coverslip was applied when dry. Microscopic evaluation of all slides was performed individually at $400 \times$ magnification by one experienced observer (animal health technician). The percentage of polymorphonuclear cells was determined in 2 different regions of the slide using a differential count of 200 cells as previously described (Denis-Robichaud and Dubuc, 2015a).

Cows were considered positive for purulent vaginal discharge when having a Metricheck score $\geq 4$ (DenisRobichaud and Dubuc, 2015a). Cows were considered positive for cytological endometritis and leukocyte esterase endometritis when having $\geq 6 \%$ polymorphonuclear cells on endometrial cytology and a score of $\geq 1$ from the leukocyte esterase test, respectively (DenisRobichaud and Dubuc, 2015a). The prevalence of purulent vaginal discharge, cytological endometritis, and leukocyte esterase endometritis was calculated for each condition by dividing the number of positive cows by the number of all cows sampled.

\section{Prolonged Anovulation}

Every cow from the cohort was also tested for prolonged anovulation by quantifying progesteronemia. Cows were bled from coccygeal vessels twice at a 14-d interval. The first sampling was at 30 to 43 DIM and the second sampling was at 44 to 57 DIM. Blood was collected into evacuated tubes without anticoagulant (Vacutainer, Becton-Dickinson and Company, Franklin Lakes, NJ) that were placed on ice, brought back to the laboratory, and allowed to clot. Within $6 \mathrm{~h}$ of collection, blood samples were centrifuged and serum was collected and frozen at $-20^{\circ} \mathrm{C}$. Serum samples were submitted to the veterinary diagnostic service of the Université de Montréal for quantification of progesteronemia using a sequential competitive ELISA (Immulite, Siemens, Mississauga, Ontario, Canada) validated for use in cattle (Martin et al., 2007). The inter- and intraassay CV of this test were 8.9 and $6.9 \%$, respectively. Cows were considered in prolonged anovulation when both samples were $<1 \mathrm{ng} / \mathrm{mL}$ (Stevenson et al., 2006). The prevalence of prolonged anovulation was calculated by dividing the number of anovular cows by the number of all cows sampled.

\section{Success at First Service and Pregnancy Loss}

All herds enrolled in the study systematically used an ovulation synchronization protocol for first service of all cows after a voluntary period of $60 \mathrm{~d}$ and exclusively used AI for breeding. Pregnancy diagnosis was performed by transrectal palpation between 32 and 45 d after the first insemination. A pregnancy confirmation was performed by transrectal palpation 2 to $4 \mathrm{wk}$ after the initial pregnancy diagnosis (at least $50 \mathrm{~d}$ after the insemination). Reproductive events and pregnancy diagnosis information were collected until 100 DIM 
because the objective was only to study first breeding performance. Cows not bred by 90 DIM or identified as "do not breed" cows after enrollment but before first service were excluded from the reproductive performance data analysis but not from the postpartum culling data analysis. The prevalence of pregnancy at first service was calculated by dividing the number of pregnant cows by the number of all cows bred at first service. Cows were considered to have a pregnancy loss if they were found not pregnant at their pregnancy confirmation exam after being found pregnant at first service. The prevalence of pregnancy loss was calculated by dividing the number of cows with pregnancy loss by the number of cows found pregnant at first service.

\section{Postpartum Culling}

Culling events were collected from enrollment in the study until 60 DIM. Cows were considered to be culled during the postpartum period if removed from the herd at $\leq 60$ DIM. The prevalence of postpartum culling was calculated by dividing the number of culled cows by the number of all cows enrolled.

\section{Management Variables and Other Diseases}

In addition to the aforementioned conditions, herdlevel variables were collected such as the season of calving during study sampling (cold season: November 1 to April 30; warm season: May 1 to October 31), the average number (herd size) and the average parity (herd parity) of lactating cows during study sampling, the housing system used for lactating cows (freestall or tie-stall), the housing system used at calving (freestall or tie-stall), and the type of bedding used at calving (straw, wood shavings, or sand). The diagnosis of displaced abomasum and retained placenta were also noted for these cohorts of cows. Displaced abomasum had to be diagnosed by a veterinarian within $\leq 60$ DIM and included left or right displaced abomasum cases. Retained placenta was diagnosed by the farmers and was defined as a retention of fetal membranes $\geq 24 \mathrm{~h}$ after calving. Farmers were trained about the definition of retained placenta before the start of the study on their farm. The prevalence of displaced abomasum or retained placenta was calculated by dividing the number of cases by the number of all cows enrolled.

\section{Statistical Analyses}

All statistical analyses were performed using SAS version 9.4 (SAS Institute Inc., Cary, NC). For every herd, prevalence of hyperketonemia, purulent vaginal discharge, cytological endometritis, leukocyte esterase endometritis, prolonged anovulation, displaced abomasum, retained placenta, pregnancy at first service, pregnancy loss, postpartum culling, and other herd variables were calculated as previously described. Herdlevel descriptive statistics were calculated, and values for the 25th, 50th, and 75th percentiles were identified (Proc MEANS in SAS).

The median prevalence of success at first service was used to stratify herds regarding their first service reproductive performance (low: value below median; high: value at or above median). Stratified first service reproductive performance was considered as a dependent variable in logistic regression models. Categorical predictors of disease prevalence were created based on the 25 th, 50 th and 75 th percentile values. All categorical predictors of diseases were tested in univariable logistic regression models. Within each disease, only one categorical predictor of disease prevalence was selected, and selection was based on the one with the lowest $P$-value. Of all predictors selected, only the ones with $P \leq 0.20$ were retained for further analysis. A multivariable model using the selected categorical predictors of disease prevalence was built with a backward elimination strategy until all remaining variables had $P \leq$ 0.05. Herd management variables (season of calving, median herd size, median herd parity, housing of lactating cows, housing at calving, and bedding at calving) were offered to this multivariable model as confounders and were kept as fixed effects if their effect on the model estimates was greater than 10\% (Maldonado and Greenland, 1993). The same approach for data analysis as for the prevalence of success at first service was used for the prevalence of pregnancy loss and of postpartum culling (logistic regression models). For all multivariable models, least squares means were calculated and differences between least squares means were tested using the Tukey-Kramer test. Statistical significance was defined as $P \leq 0.05$.

\section{RESULTS}

A total of 126 commercial dairy herds were enrolled in this study, which represented 2,520 lactating cows. These herds represented a participation rate of $93.3 \%$ $(126 / 135)$ of all herds solicited. Median herd size and herd parity were 84 (range: 28 to 360 ) and 2.8 (range: 1.7 to 4.4 ), respectively. A total of 65 herds (52\%) were sampled during the cold season, and the other herds were sampled in the warm season. Seventy herds (56\%) had lactating cows housed in tie-stall barns, whereas 56 herds $(44 \%)$ were housed in freestall barns. At calving, 84 herds $(67 \%)$ had straw as bedding material, whereas 39 herds $(31 \%)$ had wood shavings and 3 herds $(2 \%)$ had sand. Also at calving, 67 herds (53\%) were housed 
Table 1. Descriptive statistics of herd-level prevalence from 126 herds enrolled in a cohort study on prevalence of postpartum diseases and reproductive performance at first service

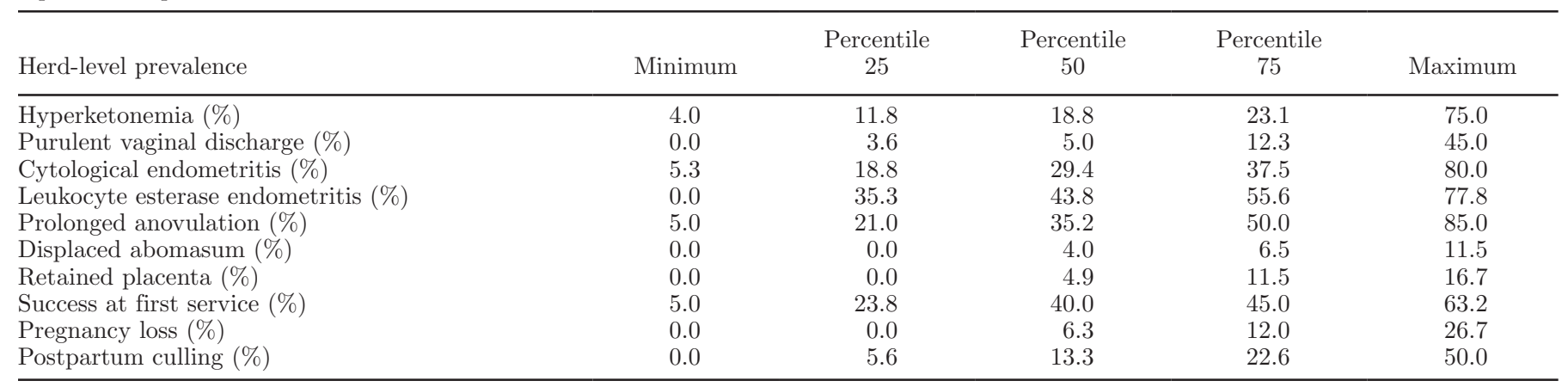

in tie-stalls, and 59 herds $(47 \%)$ were housed in calving pens. Descriptive statistics (minimum, maximum, and 25 th, 50th, and 75th percentiles) for the prevalence of postpartum diseases and culling, success at first service, and pregnancy loss are presented in Table 1. Ninety-six percent (98/102) of all displaced abomasum cases occurred within the first 30 DIM.

\section{Prevalence of Success at First Service as a Dependent Variable}

The median prevalence of success at first service was $40.0 \%$. Therefore, herds were stratified as having a low first service conception risk if $<40.0 \%$ and as having a high first service conception risk of $>40.0 \%$. We built univariable logistic regression models using the herd stratification of success at first service (high or low) as a dependent variable to identify if some predictors of disease prevalence were associated with it. We tested each quartile of disease predictors (percentiles 25, 50, and 75) in these univariable models to find the one with the lowest $P$-value. The retained predictors of a low prevalence of success at first service from univariable models were $\geq 11.8 \%$ of hyperketonemia $(P=$ $0.04), \geq 5 \%$ of purulent vaginal discharge $(P=0.04)$, $\geq 18.8 \%$ of cytological endometritis $(P<0.01), \geq 35.3 \%$ of leukocyte esterase endometritis $(P<0.01), \geq 21.0 \%$ of prolonged anovulation $(P=0.03)$, and $>4.0 \%$ of displaced abomasum $(P=0.04)$. We built a multivariable model from these variables and potential confounders. The final model included all of the retained predictors from univariable analyses, and the least squares means from this model are presented in Figure 1.

\section{Prevalence of Pregnancy Loss as a Dependent Variable}

The median prevalence of pregnancy loss was $6.3 \%$. Therefore, herds were stratified as having a low preg- nancy loss risk when $<6.3 \%$ and as having a high pregnancy loss risk when $\geq 6.3 \%$. We built univariable logistic regression models using the herd stratification of pregnancy loss risk (high or low) as a dependent variable to identify if some predictors of disease prevalence were associated with it. The retained predictors of a high prevalence of pregnancy loss from univariable models were $\geq 5.0 \%$ of purulent vaginal discharge $(P=$ $0.04), \geq 29.4 \%$ of cytological endometritis $(P=0.05)$, $\geq 55.6 \%$ of leukocyte esterase endometritis $(P=0.04)$, and $\geq 4.9 \%$ of retained placenta $(P=0.04)$. We built a multivariable model from these variables and potential confounders. The final model only included the variables purulent vaginal discharge $(P=0.01)$, retained placenta $(P=0.05)$, and season of calving $(P=0.02)$; least squares means from this model are presented in Figure 2.

\section{Prevalence of Postpartum Culling as a Dependent Variable}

The median prevalence of postpartum culling was $13.3 \%$. Therefore, herds were stratified as having a low postpartum culling risk when $<13.3 \%$ were culled and as having a high postpartum culling risk when $\geq 13.3 \%$. We built univariable logistic regression models using the herd stratification of postpartum culling risk (high or low) as a dependent variable to identify if some predictors of disease prevalence were associated with it. The retained predictors of a high prevalence of postpartum culling from univariable models were $\geq 23.1 \%$ of hyperketonemia $(P<0.01), \geq 4.0 \%$ of displaced abomasum $(P=0.03)$, and $\geq 4.9 \%$ of retained placenta $(P=0.04)$. We built a multivariable model from these variables and potential confounders. The final model included the variables hyperketonemia $(P<0.01)$, displaced abomasum $(P=0.04)$, retained placenta $(P=0.05)$, and housing of lactating cows $(P=0.04)$; least squares means from this model are presented in Figure 3. 


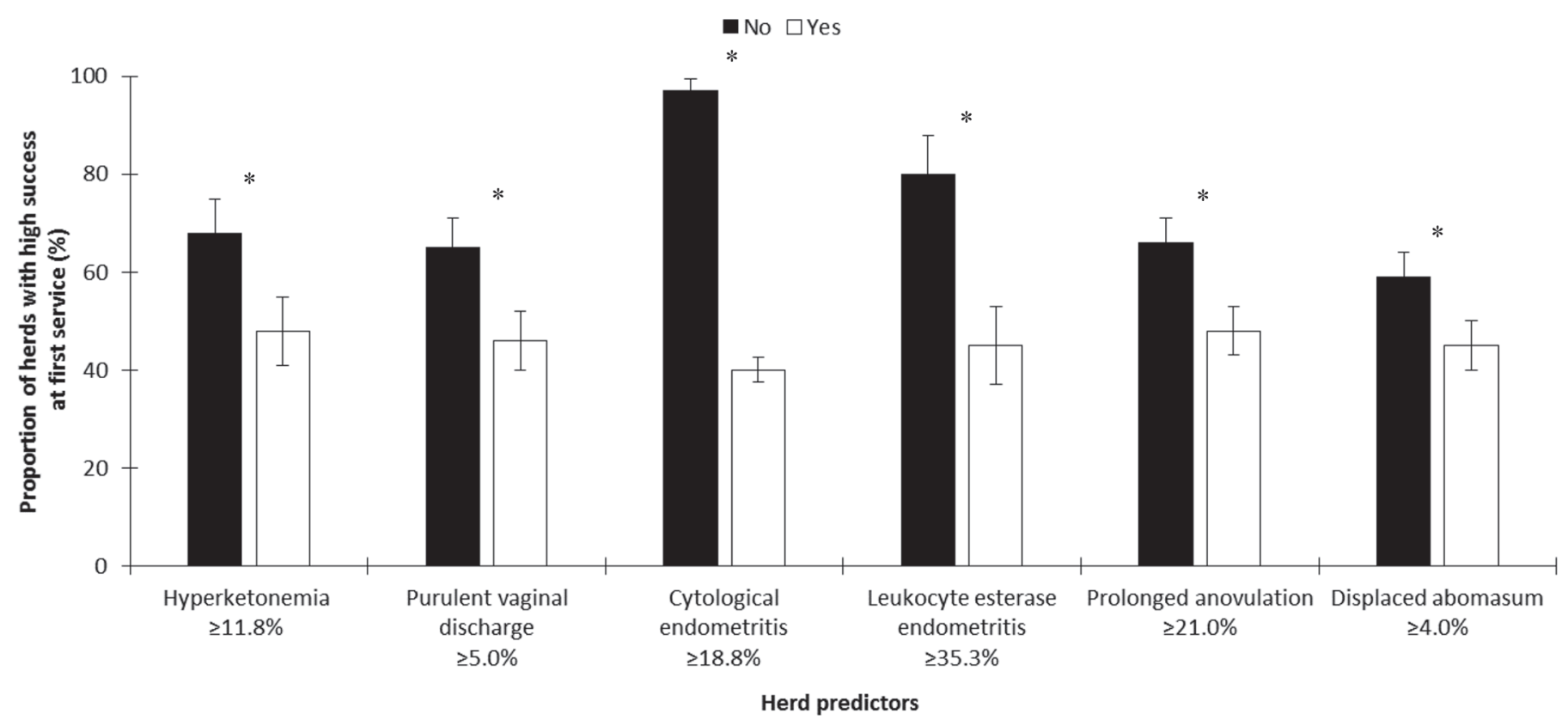

Figure 1. Least squares means $( \pm \mathrm{SEM})$ of the prevalence of success at first service in 126 dairy herds stratified by disease predictors. ${ }^{*}$ An asterisk indicates a significant effect of treatment within strata $(P<0.05)$.

\section{DISCUSSION}

This study is one of the first to investigate and quantify the herd-level prevalence of many postpartum diseases that were all diagnosed in the same cohort of cows. It is also one of the first to perform such an investigation in a sufficiently large number of herds to be able to test for associations between herd disease prevalence and herd reproductive performance at first service or postpartum culling (sufficient sample size). The participating rate of dairy farmers in this study was very high at $93 \%$ (126 participant herds/135 eli-

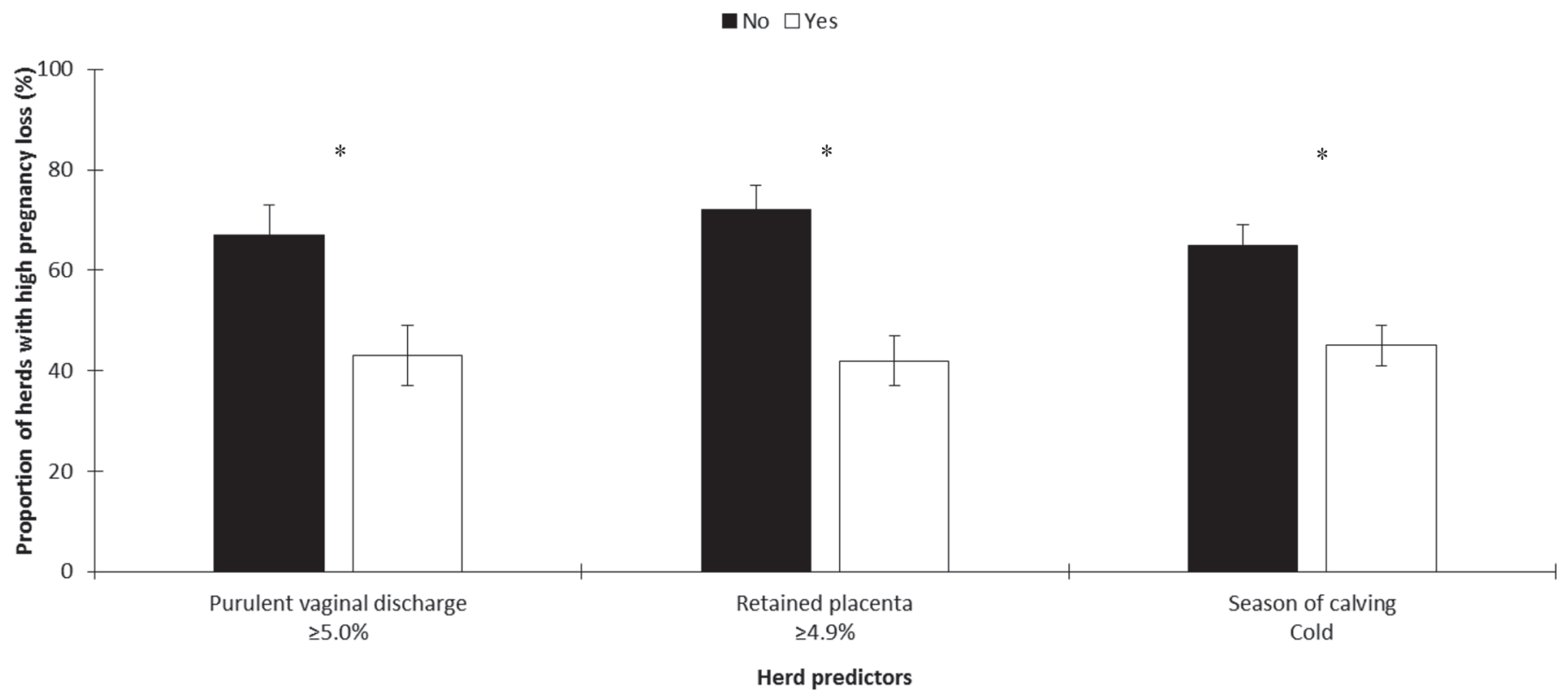

Figure 2. Least squares means $( \pm \mathrm{SEM})$ of the proportion of herds with a high pregnancy loss in 126 dairy herds stratified by disease predictors. ${ }^{*}$ An asterisk indicates a significant effect of treatment within strata $(P<0.05)$. 
gible herds) and should be considered as representative of the target population (herds enrolled in a preventive veterinary medicine program).

One major difficulty in performing this study was determining the appropriate sample size at herd and cow levels to ensure reasonable confidence of the prevalence measures while making sure that these sample size estimations are achievable in a field study enrolling a high number of herds and within budget restriction. For conditions with herd prevalence of $20 \%$, the enrolment of 20 cows per herd allowed to have a $95 \%$ confidence interval of 3 to $37 \%$ if using an $\alpha$ value of $5 \%$ (or $8-32 \%$ if using an $\alpha$ value of $20 \%$ ). Although this $95 \%$ confidence interval can be perceived as quite wide, it would have been difficult practically to enroll more than 20 cows per herds mainly because of the small herd size of the study population. This weakness of the study design has some effect on diseases with a prevalence of $20 \%$. However, for conditions with a prevalence of $5 \%$, it has to be kept in mind that the $95 \%$ confidence interval when enrolling 20 cows per herd would be 0 to $15 \%$ if using an $\alpha$ value of $5 \%$ (or $0-12 \%$ if using an $\alpha$ value of 20\%). Similarly, for conditions with prevalence of $40 \%$, the $95 \%$ confidence interval would be 20 to $60 \%$ if using an $\alpha$ value of $5 \%$ (or $25-55 \%$ if using an $\alpha$ value of $20 \%$ ). These measures of precision should be kept in mind when interpreting the results from this paper.

It should also be considered that the enrolment of cows was done at parturition, which make it very likely to have 20 cows per herd to calculate the prevalence of early postpartum diseases (hyperketonemia for example), but this number of cows could have decreased later in the postpartum period because of culling. Therefore, the calculation of success at first service for most herds was done with several cows smaller than 20 . In fact, the median number of cows used for this calculation was 17 and ranged from a minimum of 10 to a maximum of 20 cows between herds. This variation of sample size due to study design can affect the confidence interval of the estimated prevalence and this should be kept in mind when interpreting the data.

A similar situation occurred for the prevalence of pregnancy loss as the denominator of this calculation was the number of cows pregnant at first service. Therefore, the calculation was sometimes done with several cows smaller than 7 . In fact, the median number of cows used for this calculation was 8 and ranged from a minimum of 1 to a maximum of 13 cows between herds. Again, this situation can affect the confidence interval of the reported prevalence and should be considered in data interpretation.

\section{Prevalence of Hyperketonemia and Its Herd Alarm Level}

The median herd-level prevalences of many diseases were relatively similar to that found in other studies. For example, our median prevalence of hyperketonemia was $18.8 \%$, which was similar to data previously reported that were between 16 and 25\% (Duffield et al.,

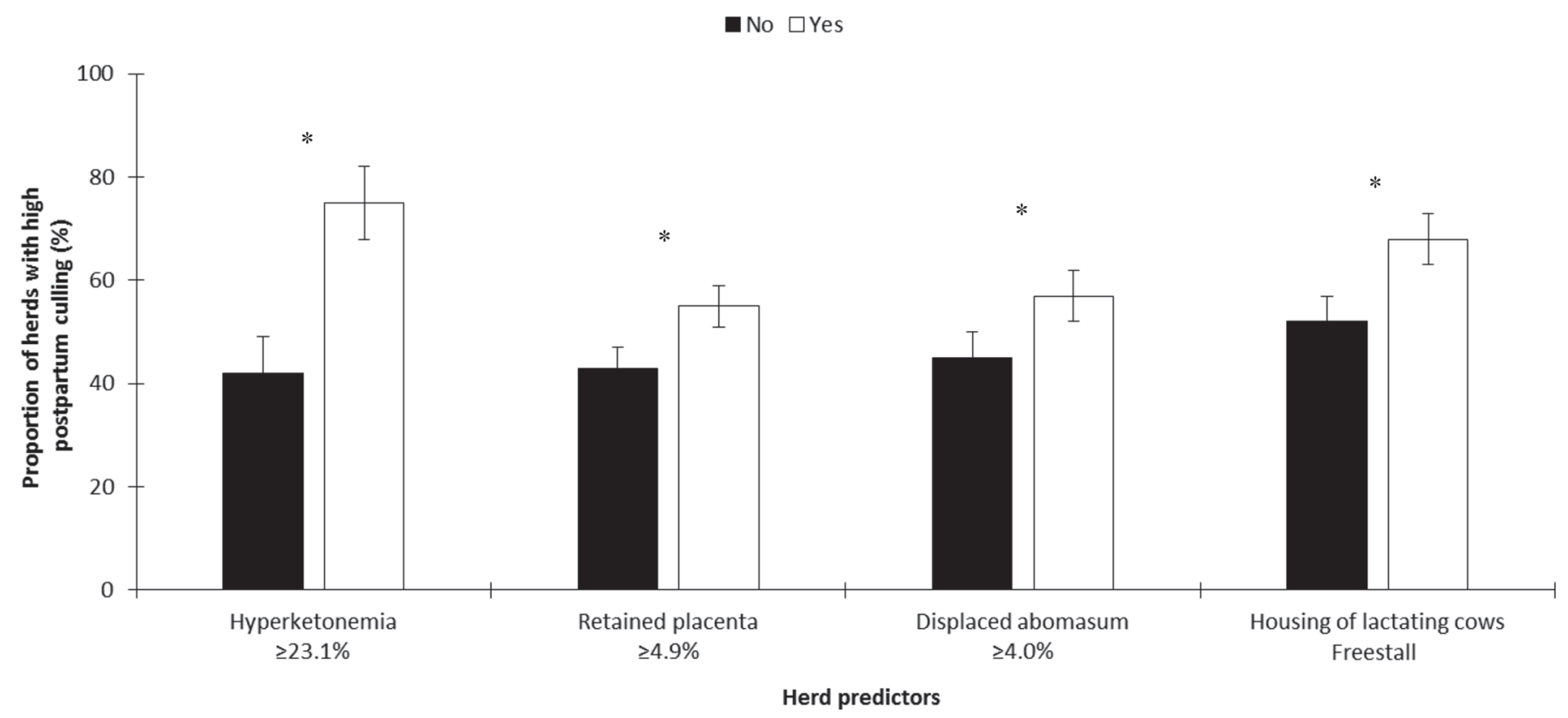

Figure 3. Least squares means $( \pm \mathrm{SEM})$ of the proportion of herds with high postpartum culling in 126 dairy herds stratified by disease predictors. ${ }^{*}$ An asterisk indicates a significant effect of treatment within strata $(P<0.05)$. 
2009; Chapinal et al., 2012b). Interestingly, the herd alarm levels for hyperketonemia previously reported were $\geq 25 \%$ (Chapinal et al., 2012b) and $\geq 15 \%$ (Ospina et al., 2010a) even if the latter used a slightly different cow-level definition of hyperketonemia $(\geq 1.2 \mathrm{mmol} / \mathrm{L}$ instead of $\geq 1.4 \mathrm{mmol} / \mathrm{L}$ ). The threshold of the current study was chosen because there are data to support it (Duffield et al., 2009), it was the threshold from Precision Xtra data showing the greatest sensitivity and specificity compared with laboratory results (Iwersen et al., 2009), and it is the most commonly used threshold by veterinarian and dairy consultants in our region. The difference between our result and the result from Chapinal et al. (2012b) could be explained by the fact that the sampling period was not exactly the same. It should be considered that the prevalence of hyperketonemia may vary within the same herd during the first weeks postpartum. Comparing the prevalence obtained when sampling cows at 1 to 14 DIM with cows sampled at 1 to 7 DIM is not exactly the same. In the present study, it was not possible to visit every herd on a weekly basis to obtain the prevalence of hyperketonemia during the first week of lactation. However, using such an approach could potentially have led to finding a higher prevalence than currently reported. Therefore, the interpretation of the reported prevalence should be done considering the specific sampling period used in this study. The alarm level in the present study was $\geq 12 \%$. No data were found in the literature about the alarm level of hyperketonemia prevalence associated with a high prevalence of postpartum culling; our results showed that this alarm level was $\geq 23 \%$. Based on these results, we recommend that the prevalence of hyperketonemia deemed acceptable on dairy farms by veterinarians and nutritionists be revised to $\geq 12 \%$ when sampling at 1 to 14 DIM and using $\geq 1.4 \mathrm{mmol} / \mathrm{L}$ as the cow-level diagnosis. This alarm level would be the lowest one associated with negative effects at the herd level.

\section{Prevalence of Retained Placenta and Displaced Abomasum and Their Herd Alarm Levels}

The median prevalence of retained placenta (4.9\%) and displaced abomasum (4.0\%) from the current study was relatively similar to other North American studies (LeBlanc et al., 2005; Ospina et al., 2010a; Chapinal et al., 2012b), although a large-scale study conducted in Europe (Berge and Vertenten, 2014) reported a slightly smaller prevalence of displaced abomasum (1.1\%). Surprisingly, data are scarce regarding the herd prevalence alarm level of these conditions based on an association with an increase in prevalence of subsequent negative effects. Based on our study, it seems appropriate to rec- ommend an alarm level of $\geq 5 \%$ for retained placenta to avoid a high prevalence of pregnancy loss and of postpartum culling, and an alarm level of $\geq 4 \%$ for displaced abomasum to avoid a low prevalence of success at first service and a high prevalence of postpartum culling.

\section{Prevalence of Purulent Vaginal Discharge and Its Herd Alarm Level}

We quantified the median prevalence of purulent vaginal discharge $(5.0 \%)$, cytological endometritis (29.4\%), and leukocyte esterase endometritis (43.8\%) in this study. We based the cow-level diagnostic criteria for these conditions on a previous work by DenisRobichaud and Dubuc (2015a) that reported optimal diagnostic criteria when diagnosed simultaneously. Such prevalence of purulent vaginal discharge may seem low but it must be kept in mind that cows were positive when they had a Metricheck score $\geq 4$, whereas most studies using a similar postpartum sampling period (30-43 DIM) used different thresholds as reported elsewhere (de Boer et al., 2014). For example, some used a score of $\geq 3$ (LeBlanc et al., 2002; Dubuc et al., 2010a) and others a score of $\geq 2$ or its equivalent (McDougall et al., 2007; Runciman et al., 2008). All of this variation in disease definition makes it hard to compare study prevalence. Little data are available in the literature about the alarm level of purulent vaginal discharge. Our results showed that a herd-level prevalence $\geq 5.0 \%$ was associated with a low prevalence of success at first service and a high prevalence of pregnancy loss for these pregnancies. The effect of purulent vaginal discharge on success at first service was not surprising (LeBlanc et al., 2002; Dubuc et al., 2011; Denis-Robichaud and Dubuc, 2015a), but the one on pregnancy loss could be explained by the suboptimal reproductive tract environment for embryo quality and survival (Hill and Gilbert, 2008). Based on these results, the alarm level for purulent vaginal discharge prevalence would be $\geq 5 \%$ when sampling at 30 to 43 DIM and using a Metricheck score $\geq 4$ as the cow-level diagnosis.

\section{Prevalence of Cytological Endometritis and Its Herd Alarm Level}

Many studies have investigated the prevalence of cytological endometritis using relatively similar cowlevel diagnostic criteria $(\geq 4-9 \%$ polymorphonuclear cells) and sampling time frames (30-50 DIM) during the postpartum period (Barlund et al., 2008; Dubuc et al., 2010a; Deguillaume et al., 2012). Those studies reported a median or a mean cytological endometritis prevalence between 11 and $45 \%$, whereas it was $29.4 \%$ 
in our study. This finding was very similar to data collected in a similar setup using a low-volume uterine lavage technique, which reported a $26 \%$ median herdlevel prevalence (Cheong et al., 2011). Although the herd-level prevalence of cytological endometritis varied largely from one herd to the other, the alarm levels found in this study that increase the risk of having a low prevalence of success at first service and a high prevalence of pregnancy loss (found in the univariable model only) were $\geq 19$ and $29 \%$, respectively. An alarm level of $\geq 19 \%$ should be used when sampling at 30 to 43 DIM and using $\geq 6 \%$ polymorphonuclear cells as a cow-level diagnosis; this alarm level is the lowest one associated with negative effects.

\section{Prevalence of Leukocyte Esterase Endometritis and Its Herd Alarm Level}

The median prevalence of leukocyte esterase endometritis was $43.8 \%$ using a cow-level diagnostic criteria of leukocyte esterase $\geq 1$ (Denis-Robichaud and Dubuc, 2015a). A similar study reported a median herd-level prevalence of $27.8 \%$ using a diagnostic criteria of leukocyte esterase $\geq 2$ (Cheong et al., 2012). The leukocyte esterase endometritis diagnostic test can provide a test result on the farm (cow side) within 2 min and allows quantification of the herd-level prevalence in a more convenient way than the cytological endometritis diagnostic procedure. Although our results from that previous study showed it did not have a perfect diagnostic agreement for cytological endometritis, we also showed that it was associated with detrimental effects on the reproductive performance of affected dairy cows (Denis-Robichaud and Dubuc, 2015a). Therefore, this cow-side diagnostic test should be considered in addition to the diagnosis of purulent vaginal discharge for investigation of herds with a low prevalence of success at first service. For such purpose, the alarm level found in this study was $\geq 35 \%$ when sampling at 30 to 43 DIM and using a leukocyte esterase score $\geq 1$ as the cow-level diagnosis.

\section{Prevalence of Prolonged Anovulation and Its Herd Alarm Level}

The median prevalence of prolonged anovulation was $35.2 \%$, which was higher than previously reported $(22.5 \%)$ in a 20-herd study (Walsh et al., 2007) and in 2 cow-level studies (22.2 and $26.2 \%$ ) on prolonged anovulation risk factors and effects (Dubuc et al., 2012; Vieira-Neto et al., 2014) conducted at a similar time during the postpartum period. The reason we documented a much higher prolonged anovulation prevalence is unclear but could be partially explained by selection bias. It is possible that herds willing to participate in the aforementioned studies had better herd management and performance, as this is generally preferred by researchers so they can have good confidence in their data. We could not find any herdlevel data in the literature about the alarm level of this condition associated with a low prevalence of success at first service. Based on our results, we suggest an alarm level of $\geq 21 \%$ of prolonged anovulation in herds (assuming individual cows are considered anovular if they have 2 progesteronemia measurements of $\leq 1 \mathrm{ng} / \mathrm{mL} 14$ $\mathrm{d}$ apart and are sampled at 30-57 DIM).

\section{Magnitude of Variation of Disease Prevalence Between Herds}

An interesting finding from this research project was the magnitude of variation of disease prevalence between herds. Having herd prevalences of hyperketonemia, displaced abomasum, and retained placenta of 4.0 to $75.0 \%, 0.0$ to $11.5 \%$, and 0.0 to $16.7 \%$, respectively, were expected as these values had been reported before (Chapinal et al., 2012b; Suthar et al., 2013; Berge and Vertenten, 2014). However, the variation in prevalence of purulent vaginal discharge, cytological endometritis, and leukocyte esterase endometritis between 0.0 and $45.0 \%, 5.3$ and $80.0 \%$, and 0.0 and $77.8 \%$, respectively, was interesting. Previous studies reported smaller (LeBlanc et al., 2002; Cheong et al., 2011) or similar (Gilbert et al., 2005; Denis-Robichaud and Dubuc, 2015b) variations than our current findings although the other studies did not always use comparable diagnostic criteria or sampling periods. A similar finding was also seen for prolonged anovulation as the range of prevalence was from 5.0 to $85.0 \%$, whereas a previous report suggested a much smaller variation (Walsh et al., 2007). Overall, the magnitude of the variation of disease prevalence was extremely wide in our study and future studies should investigate the risk factors of this situation. In other words, it is important to understand what differs in the management of one farm with a very low prevalence of disease compared with another one with a very high prevalence of disease. In any case, our results showed tremendous opportunities for dairy farmers and consultants (veterinarians and nutritionists) to work toward improving performance in reproduction and culling of their herds.

\section{Field Use of These Results}

The usefulness of these research results is widespread, from improving our scientific knowledge of herd management to improving our ability to perform herd surveillance of performance parameters. From 
a field perspective, the alarm levels presented in this manuscript could be used to identify herds at high risk of poor subsequent performance in reproduction (prevalence of $<40.0 \%$ of success at first service when using a systematic ovulation synchronization protocol; prevalence of $\geq 6.3 \%$ of pregnancy loss at first service) or in postpartum culling (prevalence of $\geq 13.3 \%$ of culling within the first 60 DIM). Alternatively, they could also be used to identify herds with poor performance in outcome measures and to help in deciding which strategy of disease surveillance could be implemented on the farm to understand the risk factors for the current situation. For example, although a herd would not undergo a systematic surveillance of purulent vaginal discharge, leukocyte esterase endometritis, and prolonged anovulation, farmers could implement surveillance of these diseases on a cohort of cows when having a low proportion of success at first service. Farmers could also prospectively implement a surveillance strategy for purulent vaginal discharge and hyperketonemia to quantify their prevalence and identify if the herd is at high risk of having a subsequent low prevalence of success at first service.

\section{CONCLUSIONS}

The prevalence of postpartum diseases, first service reproductive performance, and postpartum culling were quantified in a study population of 126 dairy herds. The prevalences varied greatly between herds and ranged from 0 to $80 \%$ for some diseases. Risk factors for herds having a low prevalence of success at first service were $\geq 11.8 \%$ hyperketonemia, $\geq 5.0 \%$ purulent vaginal discharge, $\geq 18.8 \%$ cytological endometritis, $\geq 35.3 \%$ leukocyte esterase endometritis, $\geq 21.0 \%$ prolonged anovulation, and $\geq 4.0 \%$ displaced abomasum. Risk factors for herds having a high prevalence of pregnancy loss were $\geq 5.0 \%$ purulent vaginal discharge and $\geq 4.9 \%$ retained placenta. Risk factors for herds having a high prevalence of postpartum culling were $\geq 23.1 \%$ hyperketonemia, $\geq 4.9 \%$ retained placenta, and $\geq 4.0 \%$ displaced abomasum. Further research at the herd level should investigate the reasons for such a wide variation of postpartum disease prevalence between herds.

\section{ACKNOWLEDGMENTS}

This project was financially supported by Le Ministère de l'Agriculture, des Pêcheries et de l'Alimentation du Québec (Québec, QC, Canada)-Programme Innov'Action with a research grant attributed to Jocelyn Dubuc (IA113014). This project was also financially supported by the Zoetis clinical research fund of the bovine ambulatory clinic (Université de
Montréal, St-Hyacinthe, QC, Canada). The authors deeply acknowledge Jean-Philippe Pelletier (Université de Montréal) for his technical support and the dairy farmers for their willingness to participate in the study. The authors declare no conflict of interest for this paper.

\section{REFERENCES}

Barlund, C. S., T. D. Carruthers, C. L. Waldner, and C. W. Palmer. 2008. A comparison of diagnostic techniques for postpartum endometritis in dairy cattle. Theriogenology 69:714-723.

Berge, A. C., and G. Vertenten. 2014. A field study to determine the prevalence, dairy herd management systems, and fresh cow clinical conditions associated with ketosis in western European dairy herds. J. Dairy Sci. 97:2145-2154.

Chapinal, N., M. E. Carson, S. J. LeBlanc, K. E. Leslie, S. Godden, M. Capel, J. E. P. Santos, M. W. Overton, and T. F. Duffield. 2012a. The association of serum metabolites in the transition period with milk production and early-lactation reproductive performance. J. Dairy Sci. 95:1301-1309.

Chapinal, N., S. J. LeBlanc, M. E. Carson, K. E. Leslie, S. Godden, M. Capel, J. E. P. Santos, M. W. Overton, and T. F. Duffield. 2012b. Herd-level association of serum metabolites in the transition period with disease, milk production, and early lactation reproductive performance. J. Dairy Sci. 95:5676-5682.

Cheong, S. H., D. V. Nydam, K. N. Galvão, B. M. Crosier, and R. O. Gilbert. 2011. Cow-level and herd-level risk factors for subclinical endometritis in lactating Holstein cows. J. Dairy Sci. 94:762-770.

Cheong, S. H., D. V. Nydam, K. N. Galvão, B. M. Crosier, A. Ricci, L. S. Caixeta, R. B. Sper, M. Fraga, and R. O. Gilbert. 2012. Use of reagent test strips for diagnosis of endometritis in dairy cows. Theriogenology 77:858-864.

de Boer, M. W., S. J. LeBlanc, J. Dubuc, S. Meier, W. Heuwieser, S. Arlt, R. O. Gilbert, and S. McDougall. 2014. Invited review: Systematic review of diagnostic tests for reproductive-tract infection and inflammation in dairy cows. J. Dairy Sci. 97:3983-3999.

Deguillaume, L., A. Geffré, L. Desquilbet, A. Dizien, S. Thoumire, C. Vornière, F. Constant, R. Fournier, and S. Chastant-Maillard. 2012. Effect of endocervical inflammation on days to conception in dairy cows. J. Dairy Sci. 95:1776-1783.

Denis-Robichaud, J., and J. Dubuc. 2015a. Determination of optimal diagnostic criteria for purulent vaginal discharge and cytological endometritis in dairy cows. J. Dairy Sci. 98:6848-6855.

Denis-Robichaud, J., and J. Dubuc. 2015b. Randomized clinical trial of intrauterine cephapirin infusion in dairy cows for the treatment of purulent vaginal discharge and cytological endometritis. J. Dairy Sci. 98:6856-6864.

Dohoo, I., W. Martin, and H. Stryhn. 2003. Veterinary Epidemiologic Research. 1st ed. VER Inc., Charlottetown, PEI, Canada.

Dubuc, J., T. F. Duffield, K. E. Leslie, J. S. Walton, and S. J. LeBlanc. 2010a. Definitions and diagnosis of postpartum endometritis in dairy cows. J. Dairy Sci. 93:5225-5233.

Dubuc, J., T. F. Duffield, K. E. Leslie, J. S. Walton, and S. J. LeBlanc. 2010b. Risk factors for postpartum uterine diseases in dairy cows. J. Dairy Sci. 93:5764-5771.

Dubuc, J., T. F. Duffield, K. E. Leslie, J. S. Walton, and S. J. LeBlanc. 2011. Effects of postpartum uterine diseases on milk production and culling in dairy cows. J. Dairy Sci. 94:1339-1346.

Dubuc, J., T. F. Duffield, K. E. Leslie, J. S. Walton, and S. J. LeBlanc. 2012. Risk factors and effects of postpartum anovulation in dairy cows. J. Dairy Sci. 95:1845-1854.

Duffield, T. F., K. D. Lissemore, B. W. McBride, and K. E. Leslie. 2009. Impact of hyperketonemia in early lactation dairy cows on health and production. J. Dairy Sci. 92:571-580.

Galvão, K. N., M. Frajblat, W. Butler, S. Brittin, C. Guard, and R. Gilbert. 2010. Effect of early postpartum ovulation on fertility in dairy cows. Reprod. Domest. Anim. 45:e207-e211. 
Gilbert, R. O., S. T. Shin, C. L. Guard, H. N. Erb, and M. Frajblat. 2005. Prevalence of endometritis and its effects on reproductive performance of dairy cows. Theriogenology 64:1879-1888.

Hill, J., and R. Gilbert. 2008. Reduced quality of bovine embryos cultured in media conditioned by exposure to an inflamed endometrium. Aust. Vet. J. 86:312-316.

Iwersen, M., U. Falkenberg, R. Voigtsberger, D. Forderung, and W. Heuwieser. 2009. Evaluation of an electronic cowside test to detect subclinical ketosis in dairy cows. J. Dairy Sci. 92:2618-2624.

Kasimanickam, R., T. F. Duffield, R. A. Foster, C. J. Gartley, K. E. Leslie, J. S. Walton, and W. H. Johnson. 2004. Endometrial cytology and ultrasonography for the detection of subclinical endometritis in postpartum dairy cows. Theriogenology 62:9-23.

LeBlanc, S. J., T. F. Duffield, K. E. Leslie, K. G. Bateman, G. P. Keefe, J. S. Walton, and W. H. Johnson. 2002. Defining and diagnosing postpartum clinical endometritis and its impact on reproductive performance in dairy cows. J. Dairy Sci. 85:2223-2236.

LeBlanc, S. J., K. E. Leslie, and T. F. Duffield. 2005. Metabolic predictors of displaced abomasum in dairy cattle. J. Dairy Sci. $88: 159-170$.

Maldonado, G., and S. Greenland. 1993. Simulation study of confounder-selection strategies. Am. J. Epidemiol. 138:923-936.

Martin, J. L., K. A. Vonnahme, D. C. Adams, G. P. Lardy, and R. N. Funston. 2007. Effects of dam nutrition on growth and reproductive performance of heifer calves. J. Anim. Sci. 85:841-847.

McArt, J. A. A., D. V. Nydam, and G. R. Oetzel. 2012. Epidemiology of subclinical ketosis in early lactation dairy cattle. J. Dairy Sci. 95:5056-5066.

McDougall, S., R. Macaulay, and C. Compton. 2007. Association between endometritis diagnosis using a novel intravaginal device and reproductive performance in dairy cattle. Anim. Reprod. Sci. 99:9-23.

Oetzel, G. R. 2004. Monitoring and testing dairy herds for metabolic disease. Vet. Clin. North Am. Food Anim. Pract. 20:651-674.

Ospina, P. A., D. V. Nydam, T. Stokol, and T. R. Overton. 2010a. Association between the proportion of sampled transition cows with increased nonesterified fatty acids and $\beta$-hydroxybutyrate and disease incidence, pregnancy rate, and milk production at the herd level. J. Dairy Sci. 93:3595-3601.

Ospina, P. A., D. V. Nydam, T. Stokol, and T. R. Overton. 2010b. Associations of elevated nonesterified fatty acids and $\beta$-hydroxybutyrate concentrations with early lactation reproductive performance and milk production in transition dairy cattle in the northeastern United States. J. Dairy Sci. 93:1596-1603.

Roberts, T., N. Chapinal, S. J. LeBlanc, D. F. Kelton, J. Dubuc, and T. F. Duffield. 2012. Metabolic parameters in transition cows as indicators for early-lactation culling risk. J. Dairy Sci. 95:30573063.

Runciman, D. J., G. A. Anderson, J. Malmo, and G. M. Davis. 2008 Use of postpartum vaginoscopic (visual vaginal) examination of dairy cows for the diagnosis of endometritis and the association of endometritis with reduced reproductive performance. Aust. Vet. J. 86:205-213.

Santos, J. E. P., H. M. Rutigliano, and M. F. S. Filho. 2009. Risk factors for resumption of postpartum estrous cycles and embryonic survival in lactating dairy cows. Anim. Reprod. Sci. 110:207-221.

Stevenson, J. S., J. R. Pursley, H. A. Garverick, P. M. Fricke, D. J. Kesler, J. S. Ottobre, and M. C. Wiltbank. 2006. Treatment of cycling and noncycling lactating dairy cows with progesterone during Ovsynch. J. Dairy Sci. 89:2567-2578.

Suthar, V. S., J. Canelas-Raposo, A. Deniz, and W. Heuwieser. 2013. Prevalence of subclinical ketosis and relationships with postpartum diseases in European dairy cows. J. Dairy Sci. 96:2925-2938.

Vieira-Neto, A., R. O. Gilbert, W. R. Butler, J. E. P. Santos, E. S. Ribeiro, M. M. Vercouteren, R. G. Bruno, J. H. J. Bittar, and K. N. Galvão. 2014. Individual and combined effects of anovulation and cytological endometritis on the reproductive performance of dairy cows. J. Dairy Sci. 97:5415-5425.

Walsh, R. B., D. F. Kelton, T. F. Duffield, K. E. Leslie, J. S. Walton, and S. J. LeBlanc. 2007. Prevalence and risk factors for postpartum anovulatory condition in dairy cows. J. Dairy Sci. 90:315-324. 